\title{
KUNYIT ASAM MENGURANGI NYERI HAID PADA REMAJA PUTRI
}

\author{
Cut Nur Baiti ${ }^{1}$ Astriana ${ }^{2}$, Nita Evrianasari ${ }^{3}$, Dewi Yuliasari ${ }^{4}$ \\ 1,2,3Prodi DIV Kebidanan Universitas Malahayati \\ 4Prodi DIII Kebidanan Universitas Malahayati \\ *Korespondensi email asthry_hs@yahoo.co.id
}

\section{ABSTRAC ACID TURMERIC REDUCES MENSTRUAL PAIN IN TEENAGE GIRLS}

Background: Dysmenorrhea or painful menstruation is a common gynecological problem for women of all ages. The incidence of dysmenorrhea in the world is very large. On average, more than $50 \%$ of women experience it. Turmeric drink is a drink that is processed with the main ingredient of turmeric. Naturally, turmeric does not contain active ingredients that can function as analgesics, anti-pyretics, and anti-inflammatory properties. In addition, turmeric drinks as a pain reliever in primary dysmenorrhea. A preliminary study conducted at Tri Sukses High School, there were 7 young women who could not see if tamarind turmeric helped reduce pain, so so far, if they experience menstrual pain, they take pain relievers.

Purpose: To determine the effect of tamarind turmeric on pain in adolescent girls at Tri Sukses High School, Natar District, South Lampung Regency 2019.

Methods: Quantitative Research Type. The research design used was pre-experiment with one group pretest-postest design. The sample size is 30 female teenage respondents who experience pain. In this study, the treatment was given by consuming tamarind turmeric as much as 1 cup / day during menstruation, and measuring pain before and after consuming tamarind turmeric. Sampling using purposive sampling technique. Data analysis with T-test.

Results: Based on the statistical test, it was found that the $p$ value of 0,000,000 was rejected and Ha was accepted, which means that there was an effect of giving turmeric and sour stew on menstrual pain in young women at Tri Sukses High School, Natar District, South Lampung Regency. With the mean menstrual pain before being given tamarind turmeric decoction of 6.72, median 7.00, standard deviation of 0.752 , pain scale of at least 6 and a maximum of 9 . After being given treatment, the mean was 3.67, median 4.00, standard deviation of 0.767, scale pain at least 3 and a maximum of 6 .

Conclusion: there is the effect of giving tamarind turmeric decoction on menstrual pain in Teenage Girls

Suggestion : the results of this study can be applied for young women to reduce menstrual pain complaints for girls who are menstruating.

Keywords: Turmeric Acid, Menstrual Pain,Teenage Girls

\section{ABSTRAK}

Latar Belakang: Dismenore atau menstruasi yang menimbulkan nyeri merupakan salah satu masalah ginekologi yang paling umum dialami wanita dari berbagai tingkat usia. Angka kejadian dismenore di dunia sangat besar. Rata-rata lebih dari $50 \%$ perempuan mengalaminya. Minuman kunyit adalah suatu minuman yang diolah dengan bahan utama kunyit. Secara alamiah memang kunyit dipercaya memiliki kandungan bahan aktif yang dapat berfungsi sebagai analgetika, antipiretika, dan antiinflamasi. Selain itu dijelaskan bahwa minuman kunyit sebagai pengurang rasa nyeri pada dismenore primer. Studi pendahuluan yang dilakukan di SMA Tri Sukses terdapat 7 orang remaja putri tersebut tidak mengetahui jika kunyit asam dapat membantu mengurangi nyeri haid, sehingga selama ini jika mengalami nyeri haid mereka mengkonsumsi obat pereda nyeri.

Tujuan : Untuk mengetahui adanya pengaruh kunyit asam dengan nyeri haid pada remaja putri di SMA Tri Sukses Kecamatan Natar Kabupaten Lampung selatan 2019.

Metodologi : Jenis Penelitian Kuantitatif, Rancangan penelitian yang digunakan adalah pre eksperimen dengan design one group pretest-postest. Jumlah sampel sebanyak 30 responden remaja putri yang mengalami nyeri haid. Pada penelitian ini sampel diberi perlakuan dengan mengkonsusmsi kunyit asam sebanyak 1 gelas/hari selama menstruasi, dan dilakukan pengukuran nyeri sebelum dan sesudah konsumsi kunyit asam. Dalam pengambilan sampel menggunakan teknik purposive sampling Analisa data dengan uji T-test. 


\section{JKM (Jurnal Kebidanan Malahayati),Vol 7,No.2.April 2021, \\ ISSN (Print) 2476-8944 ISSN (Online) 2579-762X, Hal 222-228}

Hasil : Berdasarkan uji statistik didapat $p$ value 0,000 artinya $\mathrm{H}_{0}$ ditolak dan $\mathrm{Ha}$ diterima, yang berarti ada Pengaruh Pemberian Rebusan Kunyit Asam Terhadap Nyeri Haid Pada Remaja Putri di SMA Tri Sukses Kecamatan Natar Kabupaten Lampung Selatan. Dengan Mean nyeri haid sebelum diberikan rebusan kunyit asam sebesar 6,72, median 7,00, standar deviasi 0,752 , skala nyeri minimal 6 dan maximal 9. Sesudah diberikanperlakuan diperoleh mean sebesar 3,67, median 4,00 , standar deviasi 0,767 , skala nyeri minimal 3 dan maximal 6.

Kesimpulan: Ada Pengaruh Pemberian Rebusan Kunyit Asam Terhadap Nyeri Haid Pada Remaja Putri

Saran : Diharapkan hasil penelitian ini dapat diaplikasikan oleh remaja putri untuk mengurangi keluhan nyeri haid bagi remaja putri yang sedang menstruasi.

Kata Kunci : Kunyit Asam, Nyeri Menstruasi,remaja

\section{PENDAHULUAN}

Masa remaja merupakan masa fase perkembangan dinamis dalam kehidupan seseorang dan merupakan periode transisi dari masa anak-anak ke masa dewasa (Sebayang 2018). Pada masa ini banyak terjadi perubahan fisik, psikis, dan biologis. Masa inilah terjadi pematangan organ reproduksi, salah satunya pada remaja putri ditandai dengan menstruasi (haid). Menstruasi adalah perdarahan vagina secara berkala akibat terlepasnya lapisan endometrium uterus (Proverawati, 2013).

Menstruasi atau haid adalah mengacu kepada pengeluaran secara periodik darah dan selsel tubuh dari vagina yang berasal dari dinding rahim wanita. Biasanya menstruasi dimulai antara 10 dan 13 tahun, tergantung pada bagian faktor termasuk kesehatan wanita, status nutrisi dan berat tubuh relative, terhadap tinggi tubuh. Menstruasi berlangsung sekali sebulan sampai wanita mencapai usia 45-50 tahun (Futri, 2017).

Umumnya saat menstruasi banyak wanita yang merasakan keluhan berupa nyeri yang berlangsung 2-3 hari, dimulai sehari sebelum mulai haid. Nyeri saat haid (dismenorea) yang dirasakan setiap wanita berbeda-beda, ada yang sedikit terganggu namun ada pula yang sangat terganggu hingga tidak dapat menjalankan aktivitas sehari-hari dan membuatnya harus istirahat bahkan terpaksa absen dari sekolah (Misliani,2019)

Menurut Proverawati, et al, (2009), saat menstruasi biasanya mengalami nyeri perut, yang biasa disebut dengan dismenorea. Dismenorea ini adalah kekakuan atau kejang di bagian bawah perut yang terjadi pada waktu menjelang atau selama menstruasi, yang memaksa wanita untuk beristirahat atau berakibat pada menurunnya kinerja dan berkurangnya aktifitas sehari-hari. Angka kejadian nyeri menstruasi (dismenore) di dunia sangat besar. Rata-rata lebih dari $50 \%$ perempuan di setiap negara mengalami dismenorea. Sementara di Indonesia angkanya diperkirakan
55\% perempuan produktif yang tersiksa oleh dismenorea. Angka kejadian (prevalensi) dismenorhea berkisar $45-95 \%$ di kalangan wanita usia produktif (Proverawati, 2009).

Dismenore atau menstruasi yang menimbulkan nyeri merupakan salah satu masalah ginekologi yang paling umum dialami wanita dari berbagai tingkat usia.(Larasati,2016) Angka kejadian dismenore di dunia sangat besar. Ratarata lebih dari $50 \%$ perempuan mengalaminya. Dari hasil penelitian di Amerika Serikat persentase kejadian dismenore sekitar $60 \%$, Swedia $72 \%$ dan di Indonesia 55\%. Penelitian di Amerika Serikat menyebutkan bahwa dismenore dialami oleh 30 $50 \%$ wanita usia reproduksi dan 10-15\% diantaranya kehilangan kesempatan kerja, mengganggu kegiatan belajar di sekolah dan kehidupan keluarga (Februanti, 2017).

Prevalensi dismenore mencapai 59,7\%. Dari mereka yang mengeluh nyeri, $12 \%$ berat, $37 \%$ sedang, dan $49 \%$ ringan. Studi ini juga melaporkan bahwa dismenore menyebabkan $14 \%$ remaja sering tidak masuk sekolah. Puncak insiden dismenore primer terjadi pada akhir masa remaja dan di awal usia 20 tahun, insiden dismenore pada remaja dilaporkan sekitar $92 \%$. Insiden ini menurun seiring dengan bertambahnya usia dan meningkatnya kelahiran (Lestari,2013).

Dampak yang ditimbulkan bagi wanita pada saat dysmenorhea yaitu fisik yang lemah, kurang gerak dan stress(Heni,2018). Karena nyeri menstruasi ini banyak wanita muda pergi ke dokter untuk konsultasi dan pengobatan. Nyeri dirasakan sebelum dan selama menstruasi sering kali muncul mual, pusing dan lemas.(Khaeronisya,2015). Nyeri ini sedemikian hebatnya sehingga memaksa penderita untuk istrahat sering kali wanita meninggalkan pekerjaanya dan bagi remaja putri banyak yang tidak hadir di sekolah serta tidak mengikuti proses pembelajaran, sehingga aktivitas pembelajaran bisa terganggu konsentrasi bisa menurun bahkan tidak ada, serta materi yang 


\section{Cut Nur Baiti, Astriana, Nita Evrianasari, Dewi Yuliasari}

diberikan selama pembelajaran yang berlangsung tidak bisa ditangkap oleh remaja putri yang mengalami dysmenorrhea (Sabaruddin,2017)

Dilaporkan lebih dari $20 \%$ remaja pubertas lebih sering tinggal di rumah untuk istirahat dan pembatasan aktifitas fisik sewaktu nyeri haid. akibat keluhan nyeri menstruasi pada remaja putri di Purworejo berdampak pada gangguan aktivitas sehari hari sehingga menyebabkan absen sekolah $<3$ hari dan tidak mampu melakukan kegiatan apapun dan ini akan menurunkan kualitas hidup pada masing-masing individu (Suri,2015). Pada umumnya $50-60 \%$ diantaranya memerlukan obat-obatan analgesik untuk mengatasi masalah nyeri menstruasi ini (Nurhalimah,2020).

Ada beberapa cara untuk meredakan gejala-gejala nyeri menstruasi yaitu dengan cara farmakologi dan non farmakologi. Obat farmakologi yang sering digunakan adalah analgesik dan anti inflamasi seperti asam mefenamat, ibuprofen, dan lain-lain. Akan tetapi penggunaan obat farmakologis menimbulkan efek samping seperti gangguan pada lambung dan penurunan pada darah (anemia). Sedangkan pengobatan non farmakologi, banyak hal yang dilakukan untuk mengurangi rasa nyeri pada dismenore primer, misalnya penggunaan kompres hangat, olahraga teratur, dan mengkonsumsi produk-produk herbal yang telah dipercaya khasiatnya (Suri 2015).

Produk herbal atau fitofarmaka saat ini memang sedang menjadi alternatif utama bagi para remaja putri yang ingin mengurangi rasa nyeri tanpa mendapat efek samping (Widatami,2018). Salah satu produk herbal yang biasa dikonsumsi dan telah familiar di masyarakat untuk mengurangi nyeri haid adalah minuman kunyit. Dalam hal ini sebagian besar masyarakat Indonesia hanya percaya bahwa memiliki kebiasaan mengkonsumsi minuman kunyit dapat mengurangi keluhan nyeri menstruasi. Namun, masyarakat tidak mengetahui kandungan dari kunyit tersebut (Winarso,2014). Data menurut IOT (Industri Obat Tradisional) dan IKOT (Industri Kecil Obat Tradisional) dari 4.187 terdapat $40 \%$ masyarakat memanfaatkan kunyit sebagai pengobatan dan 10\% masyarakat mengkonsumsi kunyit untuk mengurangi nyeri waktu haid (Suciani,2004).

Minuman kunyit adalah suatu minuman yang diolah dengan bahan utama kunyit. Secara alamiah memang kunyit dipercaya memiliki kandungan bahan aktif yang dapat berfungsi sebagai analgetika, antipiretika, dan antiinflamasi.
Selain itu dijelaskan bahwa minuman kunyit sebagai pengurang rasa nyeri pada dismenore primer memiliki efek samping minimal (Limananti \& Triratnawati, 2003). Senyawa aktif atau bahan kimia yang terkandung dalam kunyit adalah curcumine (Safitri,2018).

Curcumine akan bekerja dalam menghambat rekasi cyclooxygenase (COX-2) sehingga menghambat atau mengurangi terjadinya inflamasi sehingga akan mengurangi atau bahkan menghambat kontraksi uterus. Dan curcumenol sebagai analgetik akan menghambat pelepasan prostaglandin yang berlebihan melalui jaringan epitel uterus dan akan menghambat kontraksi uterus sehingga akan mengurangi terjadinya dismenore (Agusafutri,2017).

Penelitian Safitri (2014) dengan judul pengaruh minuman kunyit terhadap penurunan tingkat nyeri haid primer pada mahasiswi kebidanan STIKES Harapan Bangsa Purwokerto. Hasil peneitian didapatkan bahwa ada pengaruh minuman kunyit asam terhadap penurunan skala nyeri haid primer

Berdasarkan hasil prasurvey yang dilakukan di Sekolah Menengah Atas Tri Sukses dilakukan wawancara tidak terstruktur pada remaja yang kebetulan sedang mengalami nyeri haid. Pada 7 orang remaja putri, sebanyak 1 (15\%) mengungkapkan jika saat haid terasa sangat nyeri sampai kadang ijin tidak masuk kesekolah. Pada 4 $(60 \%)$ remaja putri mengatakan saat haid terjadi nyeri pinggang dan kram perut bagian bawah saat hari pertama haid, $2(25 \%)$ mengatakan saat haid seluruh bagian tubuh terasa sakit, dan lelah, sehingga kurang dapat mengikuti kegiatan saat haid hari pertama. Dari ke 7 orang remaja putri tersebut tidak mengetahui jika kunyit asam dapat membantu mengurangi nyeri haid, sehingga selama ini jika mengalami nyeri haid mereka mengkonsumsi obatobat pereda nyeri.

\section{METODE PENELITIAN}

Jenis Penelitian Kuantitatif, Rancangan penelitian yang digunakan adalah pre eksperimen dengan design one group pretest-postest. (Jaedun,2011)Jumlah sampel sebanyak 30 responden remaja putri yang mengalami nyeri haid. Pada penelitian ini sampel diberi perlakuan dengan mengkonsusmsi kunyit asam sebanyak 1 gelas/hari selama menstruasi, dan dilakukan pengukuran nyeri sebelum dan sesudah konsumsi kunyit asam. Dalam pengambilan sampel menggunakan teknik purposive sampling Analisa data dengan uji T-test. 
JKM (Jurnal Kebidanan Malahayati),Vol 7,No.2.April 2021,

ISSN (Print) 2476-8944 ISSN (Online) 2579-762X, Hal 222-228

HASIL DAN PEMBAHASAN

Analisis Univariat

Tabel 1.

Rata-Rata Nyeri Haid Pada Remaja Putri Sebelum Diberikan Kunyit Asam Di Sekolah Menengah Atas Tri Sukses Kec. Natar Kabupaten Lampung Selatan Tahun 2019

\begin{tabular}{lcccccc}
\hline Variabel & N & Mean & Median & SD & Min & Max \\
\hline $\begin{array}{l}\text { Hasil Pengukuran nyeri Haid sebelum } \\
\text { diberikan rebusan kunyit asam }\end{array}$ & 30 & 5,93 & 6,00 & 1,048 & 4 & 7 \\
\hline
\end{tabular}

Berdasarkan tabel 1 diatas dapat diketahui bahwa dari 30 responden penelitian, diperoleh hasil nilai mean atau nilai rata-rata nyeri haid sebelum diberikan rebusan kunyit asam adalah sebesar 5,93 , dengan nilai median 6,00 , standar deviasi sebesar 1,048 , hasil skala nyeri terendah atau hasil skala nyeri minimal yaitu sebesar 4 dan hasil skala nyeri tertinggi atau hasil skala nyeri maximal sebesar 7 .

Tabel 2.

Rata-Rata Nyeri Haid Pada Remaja Putri Setelah diberikan Kunyit Asam Di Sekolah Menengah Atas Tri Sukses Kec.Natar Kabupaten Lampung Selatan Tahun 2019

\begin{tabular}{lcccccc}
\hline Variabel & N & Mean & Median & SD & Min & Max \\
\hline $\begin{array}{l}\text { Hasil Pengukuran nyeri Haid sesudah diberikan } \\
\text { rebusan kunyit asam }\end{array}$ & 30 & 2,17 & 2,00 & 0,874 & 1 & 4 \\
\hline
\end{tabular}

Berdasarkan tabel 2 diatas dapat diketahui bahwa dari 30 responden penelitian, diperoleh hasil nilai mean atau nilai rata-rata nyeri haid sesudah diberikan rebusan kunyit asam adalah sebesar 2,17 , dengan nilai median 2.00 , standar deviasi sebesar 0.874 , hasil skala nyeri terendah atau hasil skala nyeri minimal yaitu sebesar 1 dan hasil skala nyeri tertinggi atau hasil skala nyeri maximal sebesar 4.

\section{Analisis Bivariat}

Tabel 3.

Pengaruh Kunyit Asam Dengan Nyeri Haid Pada Remaja Putri Di Sekolah Menengah Atas Tri Sukses Kec.Natar Kabupaten Lampung Selatan Tahun 2019

\begin{tabular}{rccccc}
\hline Hasil Pengukuran nyeri & N & Mean & SD & SE & P value \\
\hline Sebelum diberikan Intervensi & 30 & 5,93 & 1,048 & 0,191 & \multirow{2}{*}{0.000} \\
Sesudah diberikan Intervensi & 30 & 2,17 & 0,874 & 0,160 & \\
\hline
\end{tabular}

Berdasarkan tabel 3 diatas dapat diketahui hasil uji t didapat $p$ value $0,000<0.05$ artinya $\mathrm{H}_{0}$ ditolak dan Ha diterima, yang berarti ada pengaruh kunyit asam dengan nyeri haid pada remaja putri di Sekolah Menengah Atas Tri Sukses Kec. Natar Kabupaten Lampung Selatan tahun 2019.

\section{PEMBAHASAN}

Dari hasil penelitian dapat diketahui bahwa dari 30 responden penelitian, diperoleh hasil nilai mean atau nilai rata-rata nyeri haid sebelum diberikan rebusan kunyit asam adalah sebesar 5,93 , dengan nilai median 6,00 , standar deviasi sebesar 1,048, hasil skala nyeri terendah atau hasil skala nyeri minimal yaitu sebesar 4 dan hasil skala nyeri tertinggi atau hasil skala nyeri maximal sebesar 7 .

Dari hasil penelitian dapat diketahui bahwa dari 30 responden penelitian, diperoleh hasil nilai mean atau nilai rata-rata nyeri haid sesudah diberikan rebusan kunyit asam adalah sebesar 2,17 , dengan nilai median 2.00 , standar deviasi sebesar 0.874 , hasil skala nyeri terendah atau hasil skala nyeri minimal yaitu sebesar 1 dan hasil skala nyeri tertinggi atau hasil skala nyeri maximal sebesar 4.

Analisa bivariat uji $t$ test sample dependent untuk mengetahuipengaruh kunyit asam dengan nyeri haid pada remaja putri di Sekolah Menengah Atas Tri Sukses Kec.Natar Kabupaten Lampung Selatan tahun 2019. hasil uji $t$ didapat $p$ value 0,000 


\section{Cut Nur Baiti, Astriana, Nita Evrianasari, Dewi Yuliasari}

artinya $\mathrm{H}_{0}$ ditolak dan $\mathrm{Ha}$ diterima, yang berarti ada pengaruh kunyit asam dengan nyeri haid pada remaja putri di Sekolah Menengah Atas Tri Sukses Kec. Natar Kabupaten Lampung Selatan tahun 2019.

Kunyit asam merupakan salah satu jenis minuman tradisional yang sudah sangat populer di masyarakat, khususnya daerah Jawa.Minuman ini merupakan suatu minuman yang dahulu dikenal sebagai jamu tetapi karena kemajuan zaman dan efek yang ditimbulkan oleh minuman ini, saat ini minuman kunyit asam tidak dikenal sebagai jamu lagi.(Sinaga,2017)

Untuk pecinta jamu, kunyit asam adalah salah satu jamu favorit. Campuran manis dan asam yang menyegarkan tanpa rasa pahit dan getir seperti jamu-jamu lain membuat kunyit asam disukai. Selain rasanya enak ternyata jamu kunyit asam membuat tubuh menjadi langsing.Kunyit asam adalah ramuan alami yang dipercaya secara turun-temurun mengatasi berbagai keluhan kaum perempuan.Selain diyakini bisa menjaga badan tetap langsing, kunyit asam juga dipercaya mengatasi masalah menstruasi seperti nyeri haid (Aprilistyawati, A. 2011).

Menurut Sari 2012 sebelum diberikan kunyit asam di dapat kan tingkat nyeri ringan sebanyak $35 \%$ ,nyeri sedang $60 \%$ dan nyeri berat $5 \%$, setelah diberikan kunyit asam tingkat nyeri ringan $80 \%$,nyeri sedang menjadi tidak nyeri sebanyak $10 \%$ dan nyeri berat $0 \%$. Berdasarkan hasil penelitian Hamdayani 2018 yang didapatkan terdapat pengaruh pemberian minuman kunyit asam terhadap penurunan dismenore primer yaitu didapatkan ratarata pretest 5,20 dan rata-rata postest 2,40 , dengan uji statistic didapatkan nilai $p=0,006$ $(p \leq 0,05)$.Dengan adanya pengaruh pemberian minuman kunyit asam terhadap dismenore primer maka diharapkan mahasiswi dapat mengonsumsi minuman kunyit asam sebagai salah satu cara nonfarmakologi mengatasi dismenore primer

Kunyit memiliki agen-agen aktif alami yang berfungsi sebagai analgetika, antipiretika, dan antiinflamasi sedangkan asam jawa memiliki agenagen aktif yang juga berfungsi sebagai antipiretika dan penenang atau pengurang tekanan psikis.Agen aktif dalam kunyit yang berfungsi sebagai antiinflamasi dan antipiretik adalah curcumine, sebagai analgetika adalah curcumenol.Buah asam jawa, memiliki agen aktif alami anthocyanin sebagai antiinflamasi dan antipiretika (Nair, et al., 2004). Selain itu buah asam jawa juga memiliki kandungan tannins, saponins, sesquiterpenes, alkaloid, dan phlobotamins untuk mengurangi aktivitas sistem saraf (Aprilistyawati, A. 2011). Penderita nyeri haid lebih banyak terjadi saat haid pertama dan meningkat dihari kedua dan ketiga karena produksi progesteron semakin meningkat. Dari uraian diatas peneliti berpendapat bahwa faktor resiko dari dismenore pada siswi kelas XI di SMA Muhammadiyah Kudus adalah usia dan lama menstruasi.(Asroyo 2020)

Pada saat menstruasi, saat tidak ada pembuahan ovum pasca ovulasi, hormon-hormon reproduksi wanita turun drastis karena korpus luteum berinvolusi.Hal ini berakibat segala kondisi endometrium yang telah dipersiapkan sebelumnya untuk implantasi hasil fertilisasi menjadi luruh juga.Semua kelenjar meluruh, terjadi penurunan nutrisi, dan vasospasme pembuluh darah di endometrium.(Anindita,2010) Vasospasme akan menyebabkan reaksi inflamasi yang akan mengaktifkan metabolisme asam arakhidonat dan pada akhirnya akan melepaskan prostaglandin (PG). Terutama PGF2-alfa yang akan menyebabkan vasokonstriksi dan hipertonus pada miometrium. Hipertonus inilah yang akan menyebabkan dismenorea primer (Aprilistyawati, A. 2011).

Kandungan bahan alami minuman kunyit asam bisa mengurangi keluhan dismenorea primer dengan jalan masing-masing. Curcumine dan anthocyanin akan bekerja dalam menghambat rekasi cyclooxygenase (COX) sehingga menghambat atau mengurangi terjadinya inflamasi sehingga akan mengurangi atau bahkan menghambat kontraksi uterus. Mekanisme penghambatan kontraksi uterus melalui curcumine adalah dengan mengurangi influks ion kalsium (Ca2+) ke dalam kanal kalsium pada sel-sel epitel uterus. Kandungan tannins, saponins, sesquiterpenes, alkaloid, dan phlobotamins akan mempengaruhi sistem saraf otonom sehingga bisa mempengaruhi otak untuk bisa mengurangi kontraksi uterus. Dan sebagai agen analgetika, curcumenol akan menghambat pelepasan prostaglandin yang berlebihan (Aprilistyawati, A. 2011).

Menurut Marsaid 2017 Berdasarkan analisa peneliti ekstrak kunyit asam dapat menurunkan nyeri pada saat haid karena kandungan alami pada kunyit dan asam yaitu curcumine dan anthocyanin yang berfungsi menghambat reaksi cyclooxygenase (COX) dimana reaksi ini akan menghasilkan prostaglandin, prostaglandin sendiri merupakan hormon yang menyebabkan nyeri sehingga jika reaksi ini dihambat maka nyeri tidak akan timbul. Menurut Wulandari,2018 Kandungan senyawa fenolik pada kunyit dipercaya dapat digunakan sebagai antioksidan, analgetika, anti-mikroba, antiinflamasi. Secara lebih spesifik kandungan 
curcumine pada kunyit dapat menghambat terjadinya reaksi cyclooxygenase (COX) sehingga dapat menghambat dan mengurangi terjadinya inflamasi dan akan mengurangi serta menghambat kontraksi uterus yang meyebabkan nyeri haid.

Hasil Penelitian ini sejalan dengan penelitian yang telah dilakuakan oleh Agus (2014) Dengan Judul "Pengaruh Minum Kunyit Asam Terhadap Penurunan Tingkat Nyeri Dismenorea Pada Siswi Di Madrasah Tsanawiyah Negeri Jatinom Klaten" didapatkan bahwa dari 44 siswi yang mengalami menarche sebelum minum rebusan kunyit asam 33 siswi $(75 \%)$ mengalami nyeri ringan dan 11 siswi $(25 \%)$ mengalami nyeri sedang. Setelah minum kunyit asam 17 siswi $(38,6 \%)$ tidak mengalami nyeri, 21 siswi $(47,7 \%)$ nyeri ringan dan 6 siswi $(13,6 \%)$ nyeri berat. Didapatkan mean rank responden sebelum minum kunyit asam adalah 11,50 sedangkan sesudah minum kunyit asam mean rank adalah 0,00 . Hasil uji statistik didapatkan nilai $p=0,000 \quad(p<0,05) \quad$ menunjukkan adanya perbedaan derajat nyeri dismenorea sebelum dan sesudah minum kunyit asam.

Menurut telaah peneliti memberikan rebusan kunyit asam kepada remaja putri yang mengalami nyeri haid adalah suatu alternative yang sangat efektif terlihat dari hasil penelitian rata-rata nyeri haid pada remaja putri sebelum diberikan rebusan kunyit asam adalah sebesar 5,93 sedangkan ratarata nyeri haid sesudah diberikan rebusan kunyit asam sebesar 2,17. hal ini menunjukan jika remaja putri yang mengalami nyeri haid dan diberikan rebusan kunyit asam kemudian dikonsumsi setiap hari dari hari pertama menstruasi sampai hari terakhir menstruasi dapat mengurangi frekuensi nyeri yang dirasakan bahkan bisa menyembuhkan nyeri pada saat menstruasi.

Berdasarkan hasil penelitian terdapat responden dimana pengukuran skala nyeri sebelum dan sesudah diberikan kunyit asam berbeda dengan responden yang lain, yaitu penurunan skala nyeri haid lebih dari setengah dari skala nyeri sebelum diberikan rebusan kunyit asam, hal tersebut terjadi karena dipengaruhi oleh faktor karena adanya riwayat nyeri menstruasi pada keluarga yang didapatkan dari hasil wawancara dari responden sehingga respon nyeri pada setiap remaja putri berbeda-beda sehingga penurunan skala nyeri yang dirasakan remaja putri juga tidak sama antara remaja satu dengan remaja lain.

\section{SIMPULAN}

Ada Pengaruh Pemberian Rebusan Kunyit Asam Terhadap Nyeri Haid Pada Remaja Putri di SMA Tri Sukses Kecamatan Natar Kabupaten Lampung Selatan..

\section{SARAN}

Bagi remaja putri yang mengalami nyeri menstruasi dianjurkan menkonsumsi kunyit asam untuk menggurangi nyeri menstruasi dan mengurangi penggunaan obat-obatan farmakologis untuk mengatasi nyerinya.

\section{DAFTAR PUSTAKA}

Agussafutri, W. D. (2017). PERBEDAAN INTENSITAS NYERI HAID ANTARA KONSUMSI KUNYIT ASAM DAN KOMPRES HANGAT PADA MAHASISWI STIKES KUSUMA HUSADA SURAKARTA. Jurnal Kesehatan Kusuma Husada.

Anindita, A. Y. (2010). Pengaruh kebiasaan mengkonsumsi minuman kunyit asam terhadap keluhan dismenorea primer pada remaja putri di Kotamadya Surakarta.

Asroyo, T., Nugraheni, T. P., \& Masfiroh, M. A. (2020). Pengaruh Pemberian Minuman Kunyit Asam sebagai Terapi Dismenore terhadap Penurunan Skala Nyeri. Indonesia Jurnal Farmasi, 4(1), 24-28.

Aprilistyawati, A. 2011. Khasiat ramuan dan jamu tradisional. Yogyakarta : Balqist

Februanti, S. (2017). Pengetahuan Remaja Putri Tentang Penanganan Dismenore Di SMPN 9 Tasikmalaya. Jurnal Kesehatan Bakti Tunas Husada: Jurnal IImu-ilmu Keperawatan, Analis Kesehatan dan Farmasi, 17(1), 157165.

Futri, D. N. (2017). HUBUNGAN ANTARA PENGETAHUAN MENSTRUASI DENGAN PERILAKU PERSONAL HYGIENE MENSTRUASI PADA REMAJA PUTRI SMP NEGERI 2 KALIBAWANG YOGYAKARTA (Doctoral dissertation, Universitas Mercu Buana Yogyakarta).

Hamdayani, D. (2018). Pengaruh Pemberian Minuman Kunyit Asam terhadap Penurunan Dismenore Primer pada Mahasiswi Tingkat II Prodi S1 Keperawatan STIKES Mercubaktijaya Padang. Menara IImu, 12(80).

Heni Setyowati, E. R., \& Kp, S. (2018). Akupresur untuk kesehatan wanita berbasis hasil penelitian. Unimma press.

Jaedun, A. (2011). Metodologi penelitian eksperimen. Fakultas Teknik UNY, 12.

Khoerunisya, D. A. (2015). Hubungan Regulasi Emosi dengan Rasa Nyeri Haid (Dismenore) pada Remaja (Doctoral dissertation, UNIVERSITAS NEGERI SEMARANG).

Larasati, T. A., \& Alatas, F. (2016). Dismenore primer dan faktor risiko Dismenore primer pada Remaja. Jurnal Majority, 5(3), 79-84. 
Lestari, N. M. S. D. (2013, December). Pengaruh dismenorea pada remaja. In Prosiding Seminar Nasional MIPA.

Limananti, A. I., \& Triratnawati, A. (2003). Ramuan jamu cekok sebagai penyembuhan kurang nafsu makan pada anak: Suatu kajian etnomedisin. Makara Kesehatan, 7(1), 1120.

Marsaid, M., Nurjayanti, D., \& Rimbaga, Y. A. (2017). EFEKTIFITAS PEMBERIAN EKSTRAK KUNYIT ASAM TERHADAP PENURUNAN DISMENORE PADA REMAJA PUTRI. Global Health Science (GHS), 2(2).

Misliani, A., \& Firdaus, S. (2019). GAMBARAN DERAJAT DISMENORE DAN UPAYA PENANGANAN DISMENORE DENGAN CARA FARMAKOLOGI DAN NONFARMAKOLOGI PADA SISWI KELAS $X$ DI MAN 2 RANTAU. JURNAL CITRA KEPERAWATAN, 7(1), 23-32.

Nurhalimah, E., Sutrisno, S., \& Fitriani, F. (2020). EFEKTIVITAS KOMPRES JAHE DAN KOMPRES SERAI TERHADAP PENURUNAN DISMINOREA DI ASRAMA PUTRI UNIVERSITAS AN NUUR. THE SHINE CAHAYA DUNIA S-1 KEPERAWATAN, 5(2).

Proverawati, A., \& Misaroh, S. (2009). Menarche menstruasi pertama penuh makna. Yogyakarta: Nuha Medika, 144.

Proverawati, A. (2013). Anemia dalam Kehamilan. Nuha Medika: Yogyakarta.

Proverawati A. 2014. Menarche Menstruasi Pertama Penuh. Yogyakarta: Muha Medika.

Sabaruddin, H. F., Arifah, S., \& Fitriahadi, E. (2017). HUBUNGAN PENGETAHUAN TENTANG DYSMENORHEA DENGAN PERILAKU PENANGANAN DYSMENORHEA DI PESANTREN AS-SYALAFIAH MLANGI YOGYAKARTA.

Safitri, M. (2018). Efektifitas Minuman Kunyit Asam Dalam Penurunan Skala Nyeri Haid. Viva Medika: Jurnal Kesehatan, Kebidanan dan Keperawatan, 11(2), 47-53.
Safitri, M., Utami, T., \& Sukmaningtyas, W. (2014). Pengaruh Minuman Kunyit Asam Terhadap Penurunan Skala Nyeri Haid Primer Pada Mahasiswi DIII Kebidanan. In Prosiding Seminar Nasional \& Internasional.

Sari, D. K. (2012). Pengaruh Pemberian Kunyit Asam terhadap Kejadian Dismenorea pada Remaja Putri di Pedukuhan Dagen Pendowohardjo Sewon Bantul (Doctoral dissertation, STIKES'Aisyiyah Yogyakarta).

Sebayang, W., Gultom, D. Y., \& Sidabutar, E. R. (2018). Perilaku seksual remaja. Deepublish.

Suciani, S. R., \& Dewi, A. P. (2004). Efektivitas pemberian rebusan kunyit asam terhadap penurunan dismenorea (Doctoral dissertation, Riau University).

Sinaga, E., Saribanon, N., Sa'adah, N., Salamah, U., Murti, Y. A., \& Trisnamiati, A. (2017). Buku: Manajemen Kesehatan Menstruasi.

Suri, S. I., \& Nofitri, M. D. (2015). Pengaruh Minuman Kunyit Terhadap Penurunan Tingkat Nyeri Menstruasi Pada Remaja Putri Kelas 1 Di Pondok Pesantren Nurul Yaqin Pakandangan Kecamatan 6 Lingkung Kabupaten Padang Pariaman Tahun 2014. 'AFIYAH, 2(1).

Widiatami, T., Widyawati, M. N., \& Admini, A. (2018). STUDY LITERATURE TENTANG PEMBERIAN MINUMAN KUNYIT ASAM TERHADAP TINGKAT NYERI MENSTRUASI PADA REMAJA PUTRI. Jurnal Kebidanan, 8(2), 139-145.

Winarso, Agus 2014. Pengaruh Minum Kunyit Asam Terhadap Penurunan Tingkat Nyeri Dismenorea Pada Siswi Di Madrasah Tsanawiyah Negeri Jatinom Klaten.Kementerian Kesehatan Politeknik Kesehatan Surakarta Jurusan Jamu : Surakarta

Wulandari, A., Rodiani, R., \& Sari, R. D. P. (2018). Pengaruh Pemberian Ekstrak Kunyit (Curcuma longa linn) dalam Mengatasi Dismenorea. Jurnal Majority, 7(2), 193-197. 